\title{
Gallic acid suppresses the migration and invasion of PC-3 human prostate cancer cells via inhibition of matrix metalloproteinase -2 and -9 signaling pathways
}

\author{
KUO-CHING LIU ${ }^{1,5}$, AN-CHENG HUANG ${ }^{7}$, PING-PING WU ${ }^{4}$, HUI-YI LIN ${ }^{4}$, \\ FU-SHIN CHUEH ${ }^{8}$, JAI-SING YANG ${ }^{2}$, CHI-CHENG LU ${ }^{6}$, JO-HUA CHIANG ${ }^{6}$, \\ MENGHSIAO MENG ${ }^{5}$ and JING-GUNG $\mathrm{CHUNG}^{3,9}$
}

\begin{abstract}
Departments of ${ }^{1}$ Medical Laboratory Science and Biotechnology, ${ }^{2}$ Pharmacology, ${ }^{3}$ Biological Science and Technology, and ${ }^{4}$ School of Pharmacy, China Medical University, Taichung 404; ${ }^{5}$ Graduate Institute of Biotechnology and

${ }^{6}$ Department of Life Sciences, National Chung Hsing University, Taichung 402; ${ }^{7}$ Department of Nursing, St. Mary's Medicine Nursing and Management College, Yilan 266; Departments of ${ }^{8}$ Health and Nutrition Biotechnology, and ${ }^{9}$ Biotechnology, Asia University, Taichung 413, Taiwan, R.O.C.
\end{abstract}

Received February 17, 2011; Accepted March 15, 2011

DOI: $10.3892 / o r .2011 .1264$

\begin{abstract}
Epidemiological studies have demonstrated that a natural diet or consumption of fruits or vegetables can decrease the risk of cancer development. Cancer cells can migrate to and invade other organs or tissues that cause more difficulty to treat them and this also results in the need for treatments targeting multiple cellular pathways. Gallic acid (GA) has been demonstrated to possess multiple biological activities including anticancer function. However, no report exist on GA inhibited invasion and migration of human prostate cancer cells. We investigated the effects of migration and invasion in GA-treated PC-3 human prostate cancer cells with a series of in vitro experiments. Boyden chamber transwell assay was used to examine the migration and invasion of PC-3 cells. Western blotting, realtime PCR and gelatin zymography were used for determining the protein levels, gene expression and enzyme activities of matrix metalloproteinase-2 (MMP-2) and -9 in vitro. Results indicated that GA inhibited the invasion and migration of PC-3 cells and these effects are dose-dependent. GA inhibited the protein levels of MMP-2 and -9, son of sevenless homolog 1 (SOS1), growth factor receptor-bound protein 2 (GRB2), protein kinase $\mathrm{C}(\mathrm{PKC})$ and nuclear factor- $\kappa \mathrm{B}(\mathrm{NF}-\kappa \mathrm{B}) \mathrm{p} 65$, c-Jun $\mathrm{N}$-terminal kinase (JNK), extracellular signal-regulated kinase
\end{abstract}

Correspondence to: Dr Jing-Gung Chung, Department of Biological Science and Technology, China Medical University, 91, Hsueh-Shih Road, Taichung 404, Taiwan, R.O.C.

E-mail: jgchung@mail.cmu.edu.tw

Dr Menghsiao Meng, Graduate Institute of Biotechnology, National Chung Hsing University, 250 Kuo Kuang Rd., Taichung 402, Taiwan, R.O.C.

E-mail:mhmeng@dragon.nchu.edu.tw

Key words: gallic acid, cell migration, cell invasion, PC-3 human prostate cancer cells, matrix metalloproteinase-2/-9
1/2 (ERK1/2), p38, p-AKT (Thr308) and p-AKT (Ser473), but it promoted the levels of phosphatidylinositol 3-kinase (PI3K) and AKT in PC- 3 cells. GA also reduced the enzyme activities of MMP-2 and -9 in the examined cells. Moreover, the downregulation of focal adhesion kinase (FAK) and Ras homolog gene family, member A (Rho A) mRNA expression levels, and up-regulation of the tissue inhibitor of metalloproteinase-1 (TIMP1) gene levels occurred in GA-treated PC-3 cells after $24 \mathrm{~h}$ treatment. Based on these observations, we suggest that GA might modulate through blocking the p38, JNK, PKC and PI3K/AKT signaling pathways and reducing the NF- $\mathrm{KB}$ protein level, resulting in the inhibition of MMP-2 and -9 of PC-3 human prostate cancer cells.

\section{Introduction}

Prostate cancer is the most common malignancy and the second leading cause of cancer related death among men in the USA (1). In Taiwan, prostate cancer also is one of the major causes of cancer-related deaths in men and about 8 persons per 100,000 die annually from prostate cancer based on the report from Department of Health, Taiwan in 2009. That age and family history of prostate cancer are the major risk factors for prostate cancer (2). Furthermore, men with an affected father or brother are approximately twice as likely to develop the disease themselves (3). Prostate cancer has been shown to produces metastasis to the lymph nodes and bones, leading to morbidity and mortality $(4,5)$.

Treat of patients with prostate cancer includes surgery, radiation, chemotherapy, or a combination of radiotherapy and chemotherapy, but the results are still unsatisfactory. Metastasis of cancer cells makes treatment difficult as it involves invasion and migration of tumor cells. In tumor cells, the matrix metalloproteinases (MMPs) are overexpressed and the MMPs are involved in the invasion and metastasis of various tumor cells (6-8). Thus, inhibition of MMP expression 
and/or inhibition of the activities of MMP enzyme can be used as early targets for preventing cancer metastasis (9-11). Natural products from plants can inhibit cancer development (12) and can act as a cancer therapy agent (13) such as paclitaxel, which have been used in the clinic (14).

Gallic acid (3,4,5-trihydroxybenzoic acid, GA), a naturally occurring plant phenol, is abundant in natural plants (15-19) and it has been reported to have anti-bacterial (20), anti-viral (21), anti-inflammatory (16), antioxidant (22) and antitumor functions in many human cancer cell lines (21-23). Although GA has been shown to inhibit the growth of prostate cancer cells, there is no available information addressing GA-inhibited migration and invasion of prostate cancer cells in vitro. Therefore, in the present study, we focused on the in vitro antimigration and anti-invasion of GA on human prostate cancer PC-3 cells and investigated the possible signaling pathways in vitro.

\section{Materials and methods}

Materials and reagents. Gallic acid (GA), propidium iodide (PI) and dimethyl sulfoxide (DMSO) were obtained from Sigma-Aldrich Corp. (St. Louis, MO, USA). RPMI-1640 medium, L-glutamine, fetal bovine serum (FBS), penicillinstreptomycin and trypsin-EDTA were purchased from Invitrogen Life Technologies (Carlsbad, CA, USA). Primary antibodies MMP-2, MMP-9, SOS1, GRB2, PKC, NF-кB p65, JNK1/2, ERK1/2, p38, PI3K, AKT, p-AKT (Thr308), p-AKT (Ser473), $\beta$-actin and second antibodies were purchased from Santa Cruz Biotechnology, Inc. (Santa Cruz, CA, USA) and diluted in PBS Tween-20 before used for Western blot analysis.

Cell culture. The human prostate cancer PC-3 cell line was obtained from the Food Industry Research and Development Institute (Hsinchu, Taiwan). PC-3 cells were immediately cultured onto $75 \mathrm{~cm}^{2}$ tissue culture flasks with RPMI-1640 medium with $2 \mathrm{mM}$ L-glutamine were adjusted to contain supplemented with $10 \%$ FBS, 100 Units/ml penicillin and $100 \mu \mathrm{g} / \mathrm{ml}$ streptomycin and grown at $37^{\circ} \mathrm{C}$ under a humidified $5 \% \mathrm{CO}_{2}$ atmosphere.

Flow cytometric assay for cell viability. Approximately $2 \times 10^{5}$ cells/well of PC-3 cells were cultured in 12-well plates for $24 \mathrm{~h}$, and then various concentrations of GA were added to each well for final concentrations of GA at 25, 50, 100 and $150 \mu \mathrm{M}$, and $0.5 \%$ DMSO (as a control) for 24 and $48 \mathrm{~h}$. Cells were harvested from each treatment were stained with PI $(5 \mu \mathrm{g} / \mathrm{ml})$, and then analyzed by flow cytometry as previously described (24). These cells were analyzed with a flow cytometer (BD FACSCalibur, San Jose, CA, USA) equipped with an argon ion laser at $488 \mathrm{~nm}$ wavelength $(24,25)$.

In vitro wound closure. Approximately $2 \times 10^{5}$ cells/well of PC-3 cells were cultured in a 12-well plate for $24 \mathrm{~h}$ wounding by scratching with a pipet tip, and cells in the each well were incubated with serum-free RPMI-1640 medium and treated with or without GA $(0,25$ and $50 \mu \mathrm{M})$ for $24 \mathrm{~h}$. Cells were photographed using a phase-contrast microscope (x200) as previously described $(26,27)$.
In vitro invasion assay. The invasion assay of PC-3 cells was performed by using Matrigel (BD Biosciences, Bedford, MA, USA)-coated transwell cell culture chambers ( $8 \mu \mathrm{m}$ pore size, EMD Millipore, Temecula, CA, USA) as described previously (31). PC-3 cells $\left(10^{4}\right.$ cells $\left./ 0.4 \mathrm{ml}\right)$ were cultured for $24 \mathrm{~h}$ in serum-free RPMI-1640 medium and then placed in the upper chamber of the transwell insert $\left(5 \times 10^{4}\right.$ cells/well $)$ and treated with $0.5 \%$ DMSO (as a control) or GA $(25,50$ or $100 \mu \mathrm{M}$ ). However, the RPMI-1640 medium containing $10 \%$ FBS was placed in the lower chamber. All cells in each treatment were incubated for 24 or $48 \mathrm{~h}$ at $37^{\circ} \mathrm{C}$ in a humidified atmosphere with $95 \%$ air and $5 \% \mathrm{CO}_{2}$. At the end of incubation, a cotton swab was used to remove the non-invasive cells maintained in the upper chamber and the invasive cells were fixed with $4 \%$ formaldehyde in PBS and stained with $2 \%$ crystal violet in $2 \%$ ethanol and cells were counted and photographed under a light microscope at x200 magnification $(27,28)$.

In vitro migration assay. The migration assay of PC-3 cells was performed through the chemotactic directional migration by using a 24-well transwell insert. The $8 \mu \mathrm{m}$ pore filters (EMD Millipore) were coated with $30 \mu \mathrm{g}$ type I collagen (EMD Millipore) for $1 \mathrm{~h}$ and then the PC-3 cells $\left(10^{4}\right.$ cells/0.4 ml RPMI-1640) were placed in the upper chamber and treated with $0.5 \%$ DMSO (as a control) or with or without GA $(25,50$ and $100 \mu \mathrm{M})$ then to undergo migration for $24 / 48 \mathrm{~h}$. At the end of incubation, a cotton swab was used to remove the non-migrated cells in the upper chamber then the filters were individually stained with $2 \%$ crystal violet and the migrated cells adherent to the underside of the filter were examined, counted and photographed under a light microscope at x200 magnification $(26,28)$.

Cell-matrix adhesion assay. PC-3 cells ( $2 \times 10^{5}$ cells/well) were exposed to various concentrations of GA $(25,50$ and $100 \mu \mathrm{M}$ ) for 24 and $48 \mathrm{~h}$, and then seeded onto 24-well plates coated with $150 \mu$ lype I collagen (10 $\mu \mathrm{g} / \mathrm{ml})$ (EMD Millipore) overnight for $2 \mathrm{~h}$. Afterward, non-adherent cells were removed and washed with PBS, and then adherent cells were fixed in $70 \%$ ethanol for $15 \mathrm{~min}$. After being stained with $0.2 \%$ crystal violet for $10 \mathrm{~min}$, fixed cells were washed and underwent lysed in $0.2 \%$ Triton X-100 for $30 \mathrm{~min}$. The lysed solution $(150 \mu \mathrm{l})$ was added to each well of the 96 -well ELISA plates, and then the absorbance at $540 \mathrm{~nm}$ was measured as previously described $(29,30)$.

Gelatin zymography. The activities of MMP-2 and -9 in PC-3 cells were measured after exposure to various concentrations of GA. PC-3 cells $\left(5 \times 10^{5}\right.$ cells/well) plated in 12 -well tissue culture plates were incubated in serum-free RPMI-1640 medium with or without $25,50,100$ and $150 \mu \mathrm{M} \mathrm{GA}$ for 24 and $48 \mathrm{~h}$, and the conditioned medium was then collected. The collected individual medium was electrophoresed on $10 \%$ sodium dodecyl sulfate-polyacrylamide gel (SDS-PAGE) containing 0.1\% gelatin (Sigma-Aldrich Corp.). After electrophoresis, the gels were soaked in $2.5 \%$ Triton $\mathrm{X}-100$ in $\mathrm{dH}_{2} \mathrm{O}$ twice for a total of $60 \mathrm{~min}$ at $25^{\circ} \mathrm{C}$, then were

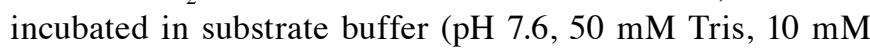
$\mathrm{CaCl}_{2}, 50 \mathrm{mM}$ and $0.05 \%$ Brij 35) at $37^{\circ} \mathrm{C}$ for $18 \mathrm{~h}$. Bands 
corresponding to activity of MMP-2 and -9 were visualized by negative staining using $0.3 \%$ Coomassie Brilliant Blue in $50 \%$ methanol and $10 \%$ acetic acid as described elsewhere (27). Quantification of the data from the band density was performed by NIH ImageJ software.

Western blot analysis. To confirm whether or not GA-affected cell migration and invasion were through the inhibition of associated protein expression, PC-3 cells $\left(1 \times 10^{6}\right.$ cells/well $)$ were placed in 6-well plates and incubated with or without GA $(25$ and $50 \mu \mathrm{M})$ for 24 and $48 \mathrm{~h}$. Cells were harvested and resuspended in ice-cold $50 \mathrm{mM}$ potassium phosphate buffer (pH 7.4) containing 2 mM EDTA and $0.1 \%$ Triton X-100 for sonication. The homogenate was centrifuged at $13000 \mathrm{~g}$ for $10 \mathrm{~min}$ at $4^{\circ} \mathrm{C}$ to remove cell debris. The supernatant was collected and total protein was quantitated using a Bio-Rad protein assay kit (Hercules, CA, USA) with bovine serum albumin (BSA) as the standard. Protein abundance of MMP-2, MMP-9, SOS1, GRB2, PKC, NF-кB p65, JNK1/2, ERK1/2, p38, PI3K, AKT, p-AKT (Thr308) and p-AKT (Ser473) (Santa Cruz Biotechnology, Inc.) were determined by SDS-PAGE and Western blotting as previously described (24-26). NIH Image J software was used to determine the band intensity from Western blot analysis.

Real-time PCR of FAK, Rho A, ROCK1, TIMP1 and TIMP2. PC-3 cells $\left(1 \times 10^{6}\right.$ cells/well) were placed in 6 -well plates and incubated without and with GA $(25$ or $50 \mu \mathrm{M})$ for $24 \mathrm{~h}$. Cells were harvested and total RNA was extracted from each treatment by using the Qiagen RNeasy Mini Kit (Qiagen, Inc., Valencia, CA, USA) as described previously $(24,25)$. RNA samples were reverse-transcribed at $42^{\circ} \mathrm{C}$ with High Capacity cDNA Reverse Transcription Kit for 30 min according to the protocol of the supplier (Applied Biosystems, Carlsbad, CA, USA). The primer sets as FAK-F: TGAATGGAACCTCG CAGTCA; FAK-R: TCCGCATGCCTTGCTTTT; Rho A-F: TCAAGCCGGAGGTCAACAAC; Rho A-R: ACGAGC TGCCCATAGCAGAA; ROCK1-F: ATGAGTTTATTCCT ACACTCTACCACTTTC; ROCK1-R: TAACATGGCAT CTTCGACACTCTAG; TIMP1-F: TGTTTATCCATCCCC TGCAAA; TIMP1-R: CAAGGTGACGGGACTGGAA; GAPDH-F: ACACCCACTCCTCCACCTTT; TIMP2-F: GGGCCAAAGCGGTCAGT; TIMP1-R: TTGAACATCT TTATCTGCTTGATCTCA; GAPDH-F: ACACCCAC TCCTCCACCTTT; GAPDH-R: TAGCCAAATTCGTTG TCATACC. Quantitative PCR conditions were: 2 min at $50^{\circ} \mathrm{C}, 10 \mathrm{~min}$ at $95^{\circ} \mathrm{C}$ and 40 cycles of $15 \mathrm{sec}$ at $95^{\circ} \mathrm{C} ; 1 \mathrm{~min}$ at $60^{\circ} \mathrm{C}$ using $1 \mu \mathrm{l}$ of the cDNA reverse-transcribed as described above, 2X SYBR Green PCR Master Mix (Applied Biosystems) and $200 \mathrm{nM}$ of forward and reverse primers. Applied Biosystems 7300 Real-Time PCR system was used for each assay in triplicate and expression fold-changes were derived using the comparative CT method $(25,27)$.

Statistical analysis. Statistical differences were performed by using the Student's t-test and considered significant at the ${ }^{*} \mathrm{p}<0.05$. All data are presented as the means $\pm \mathrm{SD}$ of three experiments.

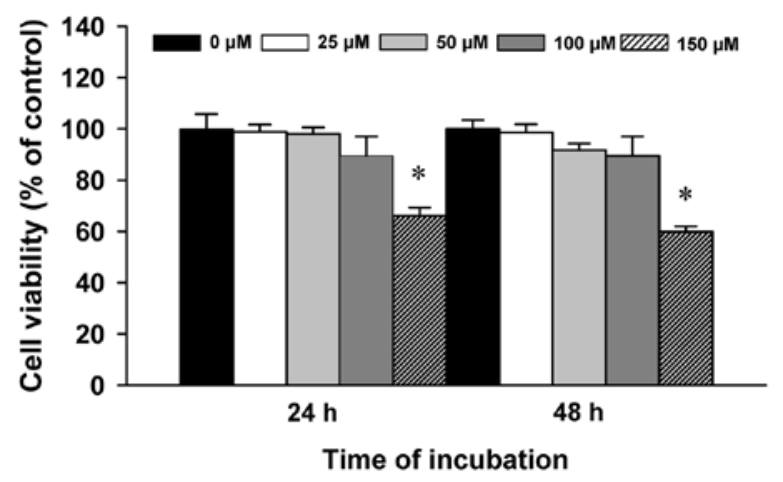

Figure 1. GA decreases the percentage of viable PC-3 cells in vitro. Cells were placed in 90\% RPMI-1640 medium + 10\% FBS with 0, 25, 50, 100 and $150 \mu \mathrm{M}$ of GA for 24 and $48 \mathrm{~h}$. The cells were collected and analyzed for viability by flow cytometry as described in Materials and methods. Each point is mean $\pm \mathrm{SD}$ of three experiments. " $\mathrm{p}<0.05$, statistically significant when compared with the untreated control.

A

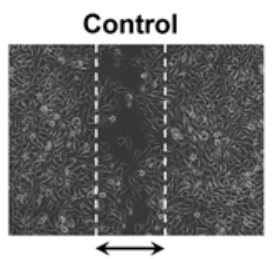
$25 \mu \mathrm{M}$
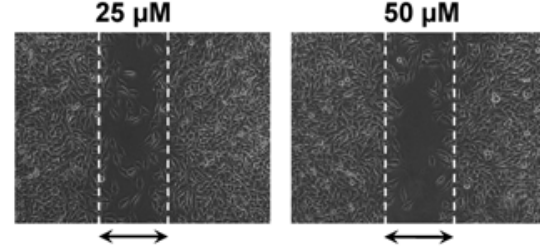

Denuded zone

B

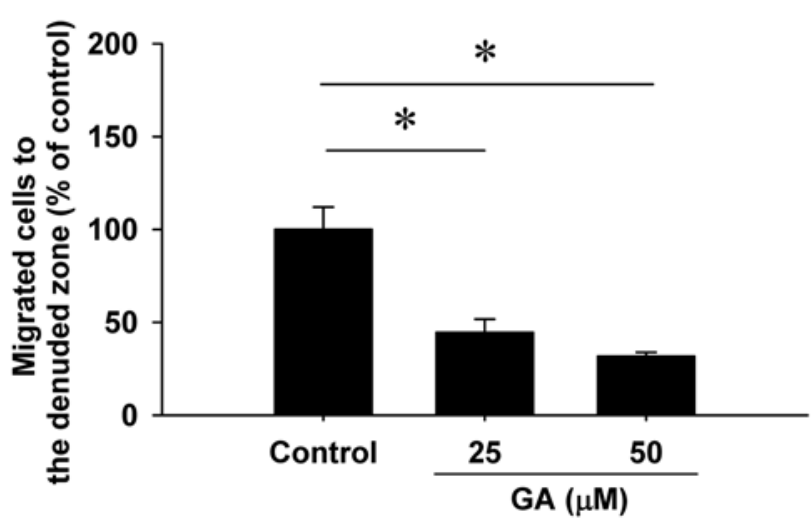

Figure 2. GA inhibits the in vitro wound closure of PC-3 cells. Confluent monolayer of PC-3 at a density of $2 \times 10^{5}$ cells/well in 12 -well plates was wounded with a scratch and rinsed by PBS to remove debris. Then, cells were incubated with or without GA ( 25 and $50 \mu \mathrm{M})$ for $24 \mathrm{~h}$ and $0.5 \%$ DMSO as control sample. The relative wound closures were monitored and photographed using a Nikon phase-contrast microscope (A). Fields shown are representative of the width of quadruplicate wounds and experiments were made in triplicate cultures. The percentage of inhibition was calculated (B). " $\mathrm{p}<0.05$, statistically significant when compared with the untreated control.

\section{Results}

$G A$ decreases the percentage of viable $P C-3$ cells in vitro. The PC-3 cells were treated with various concentrations of GA for 24 and $48 \mathrm{~h}$, and then cells from each treatment were collected for PI exclusion method for percentage of viability determination by flow cytometric assay. As shown in Fig. 1, there were 
A

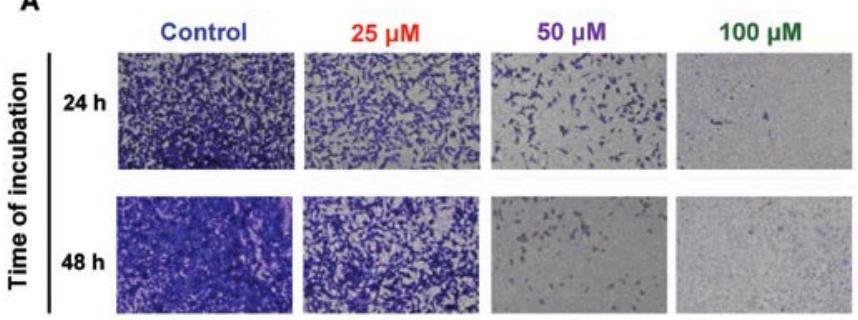

B

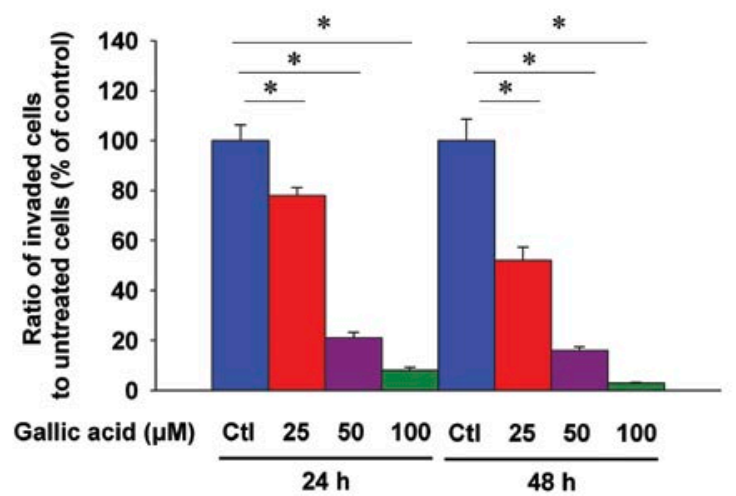

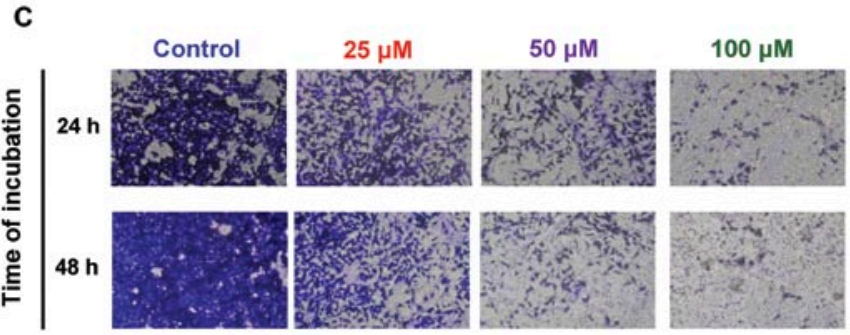

D

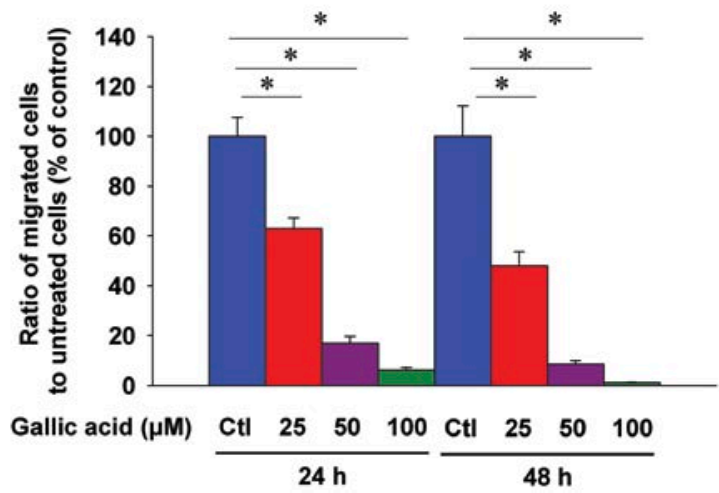

Figure 3. GA inhibits cell invasion and migration of PC-3 cells. Cells were treated with 25,50 and $100 \mu \mathrm{M}$ of GA or $0.5 \%$ DMSO as control sample (Ctl) for 24 and $48 \mathrm{~h}$. (A) Cell invasion was examined in a Boyden chamber; polycarbonate filters (pore size, $8 \mu \mathrm{m}$ ) were precoated with Matrigel; (C) cell migration was examined in a Boyden chamber and Matrigel-coated transwell with type I collagen polycarbonate filters (pore size, $8 \mu \mathrm{m}$ ); invasion (B) and migration (D) ability of PC-3 cells were quantified by counting the number of cells that invaded the underside of the porous polycarbonate membrane under microscopy and represent the average of three experiments. ${ }^{*} \mathrm{p}<0.05$, statistically significant difference between GA-treated groups and the control.

decreased the percentage of viable cells when compared to control groups $(\mathrm{p}<0.05)$ at $24-$ and 48 -h treatment of $150 \mu \mathrm{M}$ GA. Based on this result, there is no significant cytotoxic effect at $<100 \mu \mathrm{M}$ of GA in PC-3 cells.

GA inhibits the motility and in vitro wound closure of PC-3 cells. We investigated the effects of GA on migration of PC-3 cells by means of a wound closure assay. As shown in Fig. 2, relative wound closure decreased in control cells, but was higher than the GA treated cells. Fig. 2B indicates that the inhibition was at 44 and $74 \%$ when cells were incubated with GA at 25 and $50 \mu \mathrm{M}$ for a 24 -h treatment, respectively. These effects indicated that GA inhibited cell migration in a dose-dependent manner.

GA suppresses the invasion, migration and adhesion of $P C-3$ cells. To further confirm whether GA inhibited the migration of PC-3 cells, we investigated the effects of GA on invasion and migration of PC-3 cells in vitro and the results are shown in Fig. 3. The invasion assay indicates that PC-3 cells moved from the upper chamber to the lower chamber in the absence of GA (control group); however, the penetration of the Matrigel-coated filter by PC-3 cells was inhibited in the presence of GA (Fig. 3A). The percent inhibition at 25-100 $\mu \mathrm{M}$ was $22-90 \%$ and $53-96 \%$ (Fig. 3B) when PC-3 cells were incubated with GA for 24-h and 48-h treatment, respectively. The migration assay showed that GA had a significant inhibitory effect on cell migration at concentrations between 25-100 $\mu \mathrm{M}$ (Fig. 3C). Data in Fig. 3D indicate that the inhibition was $36-96 \%$ and $54-98 \%$ when cells were exposed to GA

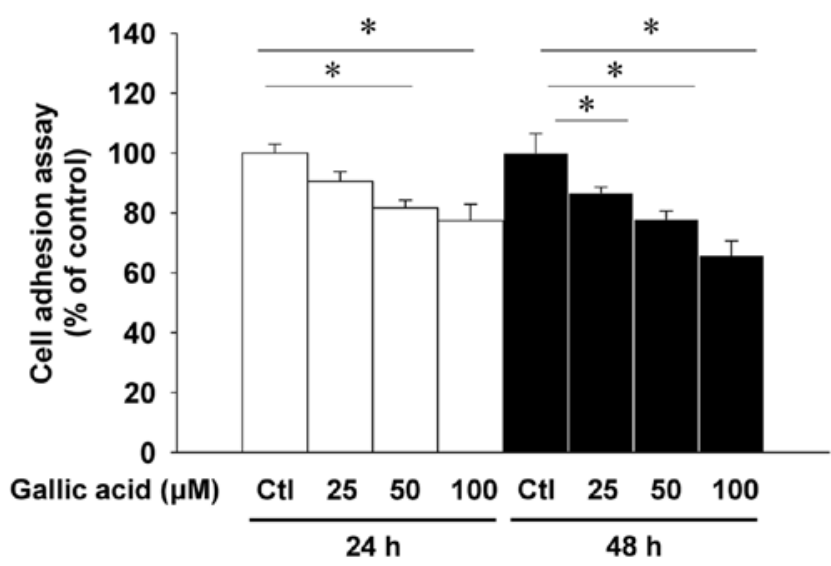

Figure 4. GA inhibited the adhesion of PC-3 cells. Cells were exposed to 25 , 50 and $100 \mu \mathrm{M}$ of GA for 24 and $48 \mathrm{~h}$, and $0.5 \%$ DMSO as control sample (Ctl). The adhesion assay was performed on 24-well plates coated with collagen (EMD Millipore) using $2 \mathrm{~h}$ incubations as described in Materials and methods. The results are presented as the percentage of vehicle-treated control $(\mathrm{Ctl})$. Each bar represents the mean \pm SD of 3 independent experiments. " $\mathrm{p}<0.05$, statistically significant when compared with the untreated control.

for $24 \mathrm{~h}$ and $48 \mathrm{~h}$, respectively. As seen in Fig. 4, a significant inhibitory effect of cell adhesion was observed in GA-treated PC-3 cells when compared to the control cells. Furthermore, these inhibitory effects of GA on PC-3 cells are not due to the cytotoxic effect of GA because the viability of these cancer cells was barely affected by GA in $150 \mu \mathrm{M}$ in the concentration range tested. 


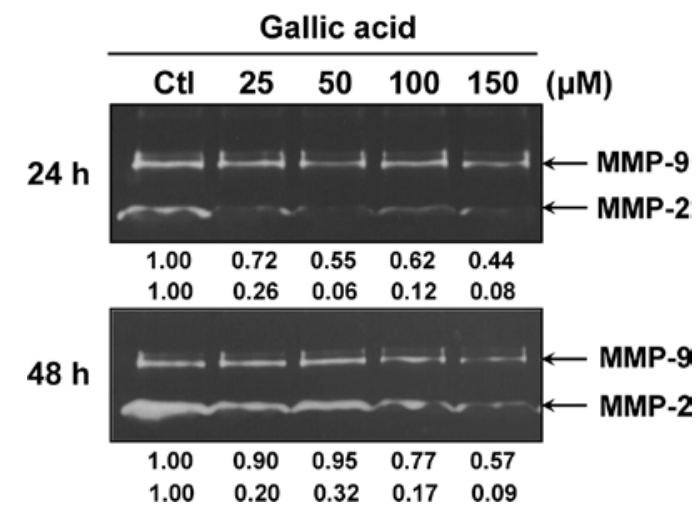

Figure 5. GA inhibits MMP-2 and MMP-9 activities in PC-3 cells. Cells $\left(5 \times 10^{5}\right.$ cells/well) were incubated with $25,50,100$ and $150 \mu \mathrm{M}$ of GA for 24 and $48 \mathrm{~h}$, and $0.5 \%$ DMSO as control sample $(\mathrm{Ctl})$. Cells were harvested and separated by gelatin zymography as described in Materials and methods. The ratios of MMP-2 and MMP-9 activities were quantitated.
GA attenuates the enzyme activities of MMP-2 and MMP-9 in $P C-3$ cells. We investigated whether GA could affect the secretion of MMP-2 and -9 in PC-3 cells. Gelatin zymography was used to analyze GA-affected MMP-2 and MMP-9 activities for 24 and $48 \mathrm{~h}$ treatment of GA $(0,25,50,100$ and $150 \mu \mathrm{M})$. The results shown in Fig. 5 indicate that GA reduced MMP-2 and MMP-9 activities in a dose-dependent manner.

GA alters the levels of proteins and gene expression associated with migration and invasion in PC-3 cells. To investigate the effects of GA on the migration and invasion associated with the inhibition of associated proteins, we determined the effects of GA on the levels of proteins associated with migration and invasion in PC-3 cells and the results are presented in Fig. 6A-D, indicating that GA reduced protein levels of MMP-2 and -9 (Fig. 6A), SOS1, GRB2, PKC and NF-кB p65 (Fig. 6B), JNK1/2, ERK1/2 and p38 (Fig. 6C) and p-AKT (Thr308) and p-AKT (Ser473) (Fig. 6D) in PC-3 cells. However, GA
A

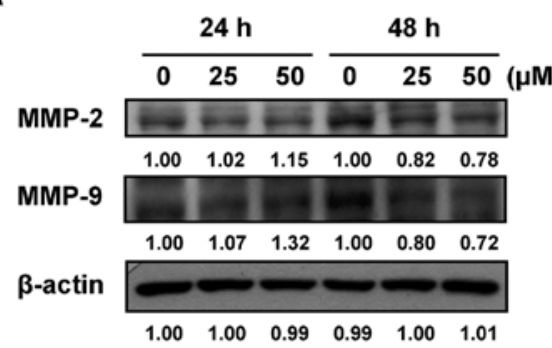

C
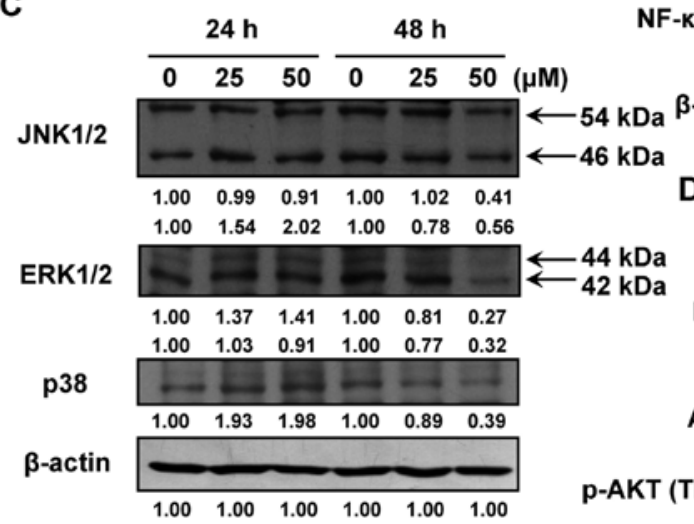

E

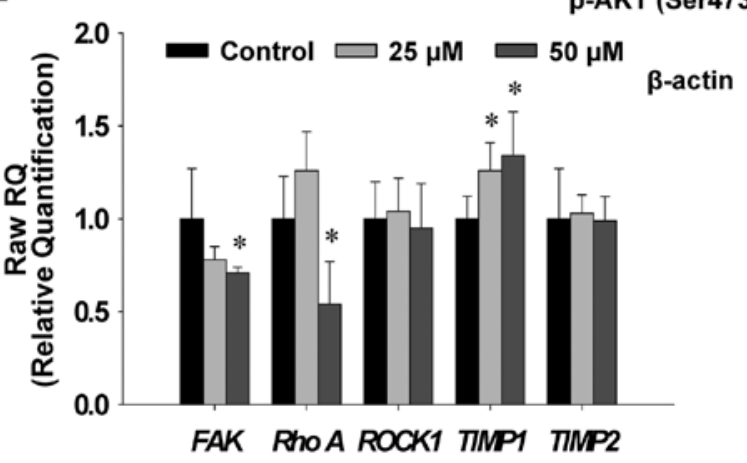

-actin

PI3K

AKT
B

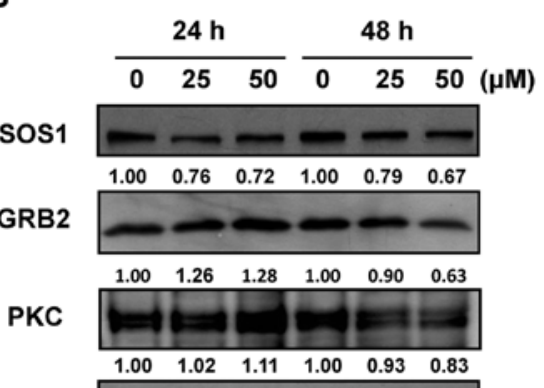

NF-KB p65

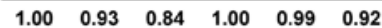

$\begin{array}{llllll}1.00 & 1.00 & 1.00 & 1.00 & 1.00 & 1.01\end{array}$

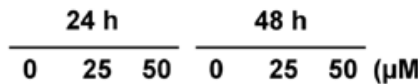

$\begin{array}{llllll}1.00 & 3.30 & 3.26 & 1.00 & 3.60 & 3.83\end{array}$

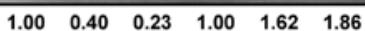

\begin{tabular}{lllllll}
\hline & & & & & & \\
1.00 & 1.57 & 1.60 & 1.00 & 0.80 & 0.57
\end{tabular}

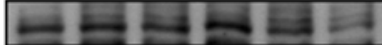

$\begin{array}{llllll}1.00 & 1.29 & 1.39 & 1.00 & 0.73 & 0.40\end{array}$

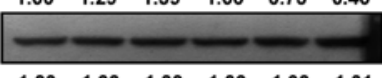

$\begin{array}{llllll}1.00 & 1.00 & 1.00 & 1.00 & 1.00 & 1.01\end{array}$

Figure 6. GA affects the migration and invasion-associated proteins and gene expression levels in PC-3 cells. Cells were treated with 0,25 and $50 \mu \mathrm{M}$ of GA for 24 and $48 \mathrm{~h}$, and $0.5 \%$ DMSO as control sample (Ctl). The total proteins were collected and the proteins levels [(A) MMP-2, MMP-9; (B) SOS1, GRB2, PKC, NF-кB p65; (C) JNK1/2, ERK1/2, p38; (D) PI3K, AKT, p-AKT (Thr308) and p-AKT (Ser473)] were examined by SDS-PAGE and Western blotting as described in Materials and methods. Cells from each treatment were harvested and the total RNA was extracted and RNA samples were reverse-transcribed for real-time PCR as described in Materials and methods. The ratios of FAK, Rho A, ROCK1, TIMP1 and TIMP2 mRNA/GAPDH (E) are presented. Data represents mean $\pm \mathrm{SD}$ of three experiments. ${ }^{*} \mathrm{p}<0.05$, statistically significantly when compared with the untreated control. 


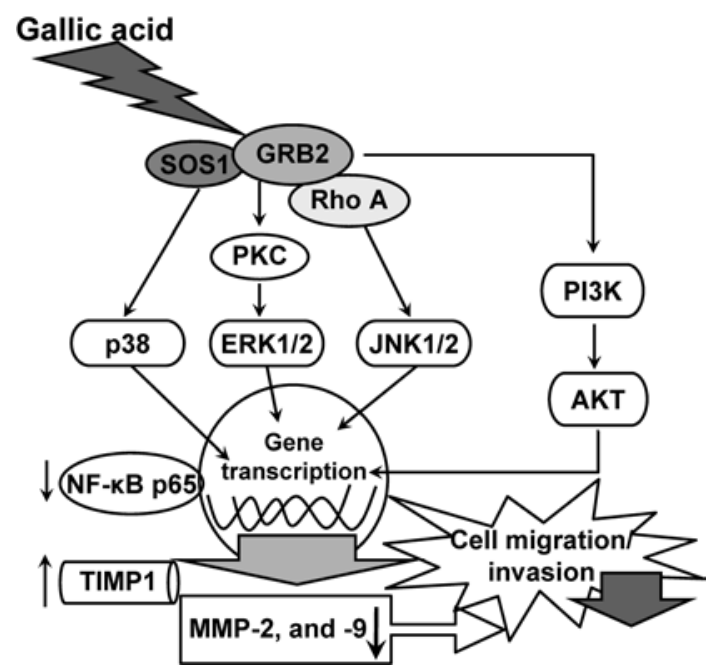

Figure 7. The proposed signaling pathways for GA-inhibited migration and invasion of PC-3 human prostate cancer cells in vitro.

promoted the levels of PI3K and AKT (Fig. 6D) in examined cells. In order to investigate whether or not GA affected migration- and invasion-associated gene expression in PC-3 cells, cells were treated with GA $(25$ and $50 \mu \mathrm{M})$ for $24 \mathrm{~h}$ and then FAK, Rho A, ROCK1, TIMP1 and TIMP2 mRNA expression were detected by real-time PCR. Results shown in Fig. 6E indicate that the mRNA expression levels of FAK and Rho A were down-regulated, and TIMP1 was up-regulated, but the levels of ROCK1 and TIMP2 were not significantly affects GA-treated PC-3 cells after $24 \mathrm{~h}$ exposure.

\section{Discussion}

It is well known that tumor metastasis occurs in many steps including vessel formation, cell attachment and adhesion, invasion, migration and cell proliferation, and these events are regulated by an extremely complex mechanism (31). Therefore, great attention is focused on developing agents or drugs that can inhibit metastasis; however, the anti-metastatic agents are still lacking (32). In the present study, we investigated the GA affects on invasion/migration of human prostate cancer PC-3 cells in vitro by using a Boyden chamber assay to quantify the migratory potential of PC-3 cells. The results indicated that GA is able to inhibit in vitro invasive and migration abilities (Fig. 3A and B) as well as decrease the adhesive capabilities (Fig. 4) in PC-3 cancer cells. Overall, our results indicate that GA decreased the metastasis of $\mathrm{PC}-3$ cells in vitro, which was determined by adhesion, invasion and migration assays.

Numerous reports have been shown that the inhibition of MMP expression and/or inhibition of the activities of MMP enzymes can be used as early targets for preventing cancer metastasis (9,32-33). MMP-2 (72-kDa gelatinase A) and MMP-9 (92-kDa gelatinase B) are involved in the invasive metastatic potential of tumor cells (34). Our results from wound healing and invasion assays also showed that GA inhibited the invasion and migration (Figs. 2 and 3) and it also reduced cell adhesion (Fig. 4) in PC-3 cells in vitro. GA inhibited the activities of MMP-2 and -9 which are involved in degradation of extracellular matrix and play important roles in cancer cell migration and invasion (34-37). Our results demonstrated that anti-metastastic effects of GA were associated with the inhibition of enzymatically degradative processes of metastasis in PC-3 cells (Fig. 5). The present results suggest that GA may have efficacy, if delivered to the bone site at concentrations between 20-40 $\mu \mathrm{M}$, thus preventing metastasis of bone cancer cells.

GA also inhibited associated protein levels such as MMP-2 and -9 (Fig. 6A), SOS1, GRB2, PKC and NF- $\kappa$ B p65 (Fig. 6B), JNK, ERK1/2 and p38 (Fig. 6C) and p-AKT (Thr 308) and p-AKT (Ser-473) (Fig. 6D). GA inhibited the levels of ERK1/2 which is the key molecules of the extracellular signal-regulated kinase (ERK) signaling pathway that has been shown to promote tumor invasion and metastasis (Fig. 6C). The ERK signaling pathway up-regulated the expression of MMPs (30). We thus tested the effect of GA on the ERK signaling pathway. We found that GA inhibited the phosphorylation of AKT (Fig. 6D) in PC-3 cells, indicating that GA can inhibit the AKT signaling pathway.

Furthermore, the results indicated that GA also decreased the levels of AKT, p-AKT and JNK1/2 (Fig. 6C and D) in PC-3 cells. This is in agreement with other report that integrins activate MAPK and PI3K, leading to activation of AKT (37). Our results also showed that GA inhibited the levels of AKT, FAK, ROCK 1 and Rho A that may lead to inhibit the levels of MMP-2 and -9 in PC-3 cells, contributing to the decrease in migration of GA-treated PC-3 cells. It was reported that PI3K activation stimulated the downstream target AKT which associated with cell invasion $(38,39)$. Other investigators have pointed out that PI3K activation stimulated the downstream target AKT, and AKT plays various and important roles in cell invasion (38-40) and the activation of ERK and AKT are involved in the development of endometrial cancer $(41,42)$. Herein, our findings showed that GA inhibited the protein levels of PI3K, AKT, PKC, NF- $\mathrm{B}$, MMP-2 and MMP-9 in PC-3 cells in vitro. Furthermore, the activation of $\mathrm{PKC}$ could lead to the translocation of the protein to membranes for affecting the expression of MMP-9 through NF- $\kappa$ B or Sp-1 via mitogenactivated protein kinase (MAPK) and phosphoinositide 3-kinase (PI3K) signaling pathways (32,43-46). Based on results from real-time PCR GA inhibited the gene expression of FAK and Rho A, but promoted TIMP1 mRNA level of PC-3 cells (Fig. 6E). TIMP1 has been shown to regulate MMP2 activity and numerous pieces of evidence have indicated a correlation between elevated TIMP1 levels and diminished MMP-2 activity and invasiveness (46-48).

Collectively, GA has multiple anti-metastatic activities and has the potential to be developed into an anti-metastatic agent for prostate cancer. The possible signal pathways for GA to inhibit migration and invasion in PC-3 cells may be through down-regulation of PKC, p38, ERK, JNK and PI3K/ AKT signaling pathways and $\mathrm{NF}-\kappa \mathrm{B}$ resulting in inhibition of MMP-2 and MMP-9 (Fig. 7). The in vivo efficacy studies with GA should be done in animal models in future investigations. 


\section{Acknowledgements}

This study was supported by a grant CMU99-TC-13 from China Medical University, Taichung, Taiwan.

\section{References}

1. Hernandez BY, Green MD, Cassel KD, Pobutsky AM, Vu V and Wilkens LR: Preview of Hawaii Cancer Facts and Figures 2010. Hawaii Med J 69: 223-224, 2010.

2. Williams H and Powell IJ: Epidemiology, pathology, and genetics of prostate cancer among African Americans compared with other ethnicities. Methods Mol Biol 472: 439-453, 2009.

3. Steinberg GD, Carter BS, Beaty TH, Childs B and Walsh PC: Family history and the risk of prostate cancer. Prostate 17: 337-347, 1990

4. Koeneman KS, Yeung F and Chung LW: Osteomimetic properties of prostate cancer cells: a hypothesis supporting the predilection of prostate cancer metastasis and growth in the bone environment. Prostate 39: 246-261, 1999.

5. Koutsilieris M: Osteoblastic metastasis in advanced prostate cancer. Anticancer Res 13: 443-449, 1993.

6. Kilian M, Gregor JI, Heukamp I, et al: Matrix metalloproteinase inhibitor RO 28-2653 decreases liver metastasis by reduction of MMP-2 and MMP-9 concentration in BOP-induced ductal pancreatic cancer in Syrian Hamsters: inhibition of matrix metalloproteinases in pancreatic cancer. Prostaglandins Leukot Essent Fatty Acids 75: 429-434, 2006.

7. Mizutani K, Kofuji K and Shirouzu K: The significance of MMP-1 and MMP-2 in peritoneal disseminated metastasis of gastric cancer. Surg Today 30: 614-621, 2000.

8. Gullu IH, Kurdoglu M and Akalin I: The relation of gelatinase (MMP-2 and -9) expression with distant site metastasis and tumour aggressiveness in colorectal cancer. Br J Cancer 82: 249, 2000.

9. Guruvayoorappan C and Kuttan G: Amentoflavone inhibits experimental tumor metastasis through a regulatory mechanism involving MMP-2, MMP-9, prolyl hydroxylase, lysyl oxidase, VEGF, ERK-1, ERK-2, STAT-1, NM23 and cytokines in lung tissues of C57BL/6 mice. Immunopharmacol Immunotoxicol 30 711-727, 2008

10. Okada N, Ishida H, Murata N, Hashimoto D, Seyama Y and Kubota S: Matrix metalloproteinase-2 and -9 in bile as a marker of liver metastasis in colorectal cancer. Biochem Biophys Res Commun 288: 212-216, 2001.

11. Waas ET, Wobbes T, Lomme RM, DeGroot J, Ruers T and Hendriks T: Matrix metalloproteinase 2 and 9 activity in patients with colorectal cancer liver metastasis. Br J Surg 90: 1556-1564, 2003.

12. Hong WK and Sporn MB: Recent advances in chemoprevention of cancer. Science 278: 1073-1077, 1997.

13. AbouEl Hassan MA, Braam SR and Kruyt FA: Paclitaxel and vincristine potentiate adenoviral oncolysis that is associated with cell cycle and apoptosis modulation, whereas they differentially affect the viral life cycle in non-small cell lung cancer cells. Cancer Gene Ther 13: 1105-1114, 2006.

14. Fung-Kee-Fung M, Oliver T, Elit L, Oza A, Hirte HW and Bryson P: Optimal chemotherapy treatment for women with recurrent ovarian cancer. Curr Oncol 14: 195-208, 2007.

15. Ng TB, He JS, Niu SM, et al: A gallic acid derivative and polysaccharides with antioxidative activity from rose (Rosa rugosa) flowers. J Pharm Pharmacol 56: 537-545, 2004.

16. Kim SH, Jun CD, Suk K, et al: Gallic acid inhibits histamine release and pro-inflammatory cytokine production in mast cells. Toxicol Sci 91: 123-131, 2006.

17. Chakraborty A, Ferk F, Simic T, et al: DNA-protective effects of sumach (Rhus coriaria L.), a common spice: results of human and animal studies. Mutat Res 661: 10-17, 2009.

18. Shahrzad S, Aoyagi K, Winter A, Koyama A and Bitsch I: Pharmacokinetics of gallic acid and its relative bioavailability from tea in healthy humans. J Nutr 131: 1207-1210, 2001.

19. Atkinson BL, Blackman AJ and Faber $\mathrm{H}$ : The degradation of the natural pyrethrins in crop storage. J Agric Food Chem 52: 280-287, 2004.

20. Kang MS, Oh JS, Kang IC, Hong SJ and Choi CH: Inhibitory effect of methyl gallate and gallic acid on oral bacteria. J Microbiol 46: 744-750, 2008.
21. Kaur M, Velmurugan B, Rajamanickam S, Agarwal R and Agarwal C: Gallic acid, an active constituent of grape seed extract, exhibits anti-proliferative, pro-apoptotic and antitumorigenic effects against prostate carcinoma xenograft growth in nude mice. Pharm Res 26: 2133-2140, 2009.

22. Inoue M, Suzuki R, Koide T, Sakaguchi N, Ogihara Y and Yabu Y: Antioxidant, gallic acid, induces apoptosis in HL-60RG cells. Biochem Biophys Res Commun 204: 898-904, 1994.

23. Veluri R, Singh RP, Liu Z, Thompson JA, Agarwal R and Agarwal C: Fractionation of grape seed extract and identification of gallic acid as one of the major active constituents causing growth inhibition and apoptotic death of DU145 human prostate carcinoma cells. Carcinogenesis 27: 1445-1453, 2006.

24. Lu CC, Yang JS, Huang AC, et al: Chrysophanol induces necrosis through the production of ROS and alteration of ATP levels in J5 human liver cancer cells. Mol Nutr Food Res 54: 967-976, 2010.

25. Chiang JH, Yang JS, Ma CY, et al: Danthron, an anthraquinone derivative, induces DNA damage and caspase cascades-mediated apoptosis in SNU-1 human gastric cancer cells through mitochondrial permeability transition pores and Bax-triggered pathways. Chem Res Toxicol 24: 20-29, 2011

26. Chen YY, Chiang SY, Lin JG, et al: Emodin, aloe-emodin and rhein inhibit migration and invasion in human tongue cancer SCC-4 cells through the inhibition of gene expression of matrix metalloproteinase-9. Int J Oncol 36: 1113-1120, 2010.

27. Lai KC, Huang AC, Hsu SC, et al: Benzyl isothiocyanate (BITC) inhibits migration and invasion of human colon cancer HT29 cells by inhibiting matrix metalloproteinase-2/-9 and urokinase plasminogen (uPA) through PKC and MAPK signaling pathway. J Agric Food Chem 58: 2935-2942, 2010.

28. Lin HJ, Su CC, Lu HF, et al: Curcumin blocks migration and invasion of mouse-rat hybrid retina ganglion cells (N18) through the inhibition of MMP-2, -9, FAK, Rho A and Rock-1 gene expression. Oncol Rep 23: 665-670, 2010.

29. Chen PN, Hsieh YS, Chiang CL, Chiou HL, Yang SF and Chu SC: Silibinin inhibits invasion of oral cancer cells by suppressing the MAPK pathway. J Dent Res 85: 220-225, 2006.

30. Chen PN, Chu SC, Chiou HL, Kuo WH, Chiang CL and Hsieh YS: Mulberry anthocyanins, cyanidin 3-rutinoside and cyanidin 3-glucoside, exhibited an inhibitory effect on the migration and invasion of a human lung cancer cell line. Cancer Lett 235: 248-259, 2006.

31. Fidler IJ: The organ microenvironment and cancer metastasis. Differentiation 70: 498-505, 2002.

32. Chakraborti S, Mandal M, Das S, Mandal A and Chakraborti T: Regulation of matrix metalloproteinases: an overview. Mol Cell Biochem 253: 269-285, 2003

33. Coussens LM and Werb Z: Matrix metalloproteinases and the development of cancer. Chem Biol 3: 895-904, 1996.

34. Zhang L, Shi J, Feng J, Klocker H, Lee C and Zhang J: Type IV collagenase (matrix metalloproteinase-2 and -9) in prostate cancer. Prostate Cancer Prostatic Dis 7: 327-332, 2004.

35. Bjornland K, Flatmark K, Pettersen S, Aaasen AO, Fodstad O and Maelandsmo GM: Matrix metalloproteinases participate in osteosarcoma invasion. J Surg Res 127: 151-156, 2005.

36. Overall CM and Kleifeld O: Tumour microenvironment opinion: validating matrix metalloproteinases as drug targets and anti-targets for cancer therapy. Nat Rev Cancer 6: 227-239, 2006.

37. Duffy MJ: The urokinase plasminogen activator system: role in malignancy. Curr Pharm Des 10: 39-49, 2004.

38. Eccles SA: Parallels in invasion and angiogenesis provide pivotal points for therapeutic intervention. Int J Dev Biol 48: 583-598, 2004.

39. Hollborn M, Stathopoulos C, Steffen A, Wiedemann P, Kohen L and Bringmann A: Positive feedback regulation between MMP-9 and VEGF in human RPE cells. Invest Ophthalmol Vis Sci 48: 4360-4367, 2007.

40. Carpenter CL and Cantley LC: Phosphoinositide kinases. Curr Opin Cell Biol 8: 153-158, 1996.

41. Allen NE, Key TJ, Dossus L, et al: Endogenous sex hormones and endometrial cancer risk in women in the European Prospective Investigation into Cancer and Nutrition (EPIC). Endocr Relat Cancer 15: 485-497, 2008.

42. Osipo C, Meeke K, Liu H, et al: Trastuzumab therapy for tamoxifen-stimulated endometrial cancer. Cancer Res 65: 8504-8513, 2005. 
43. Zhang S, Li Z, Wu X, Huang Q, Shen HM and Ong CN: Methyl3 -indolylacetate inhibits cancer cell invasion by targeting the MEK1/2-ERK1/2 signaling pathway. Mol Cancer Ther 5: 3285-3293, 2006.

44. Chung TW, Lee YC and Kim CH: Hepatitis B viral HBx induces matrix metalloproteinase-9 gene expression through activation of ERK and PI-3K/AKT pathways: involvement of invasive potential. FASEB J 18: 1123-1125, 2004.

45. Simon C, Simon M, Vucelic G, et al: The p38 SAPK pathway regulates the expression of the MMP-9 collagenase via AP-1dependent promoter activation. Exp Cell Res 271: 344-355, 2001.
46. Khokha R, Zimmer MJ, Graham CH, Lala PK and Waterhouse P: Suppression of invasion by inducible expression of tissue inhibitor of metalloproteinase-1 (TIMP-1) in B16-F10 melanoma cells. J Natl Cancer Inst 84: 1017-1022, 1992.

47. Park MJ, Lee JY, Kwak HJ, et al: Arsenic trioxide (As2O3) inhibits invasion of HT1080 human fibrosarcoma cells: role of nuclear factor-kappaB and reactive oxygen species. J Cell Biochem 95: 955-969, 2005.

48. Ramer R and Hinz B: Inhibition of cancer cell invasion by cannabinoids via increased expression of tissue inhibitor of matrix metalloproteinases-1. J Natl Cancer Inst 100: 59-69, 2008. 